\title{
Action Research and Public Relations: Dialogue, Peer Learning, and the Issue of Alcohol
}

Magda Pieczka and Emma Wood

Queen Margaret University, UK

Public Relations Inquiry, Reprints and permissions:

sagepub.co.uk/journalsPermissions.nav DOI: 10.1177/2046147X13485955

pri.sagepub.com

\section{Abstract}

This article presents an action research project that transformed dialogic techniques, used in policy making and community development into an innovative approach to education about alcohol. The project was developed by a group of teenage volunteers, the AlcoLOLs, and two public relations researchers, tested in a local school, presented at the Scottish Parliament to policy stakeholders concerned with alcohol, and subsequently extended to a number of schools across the city of Edinburgh (Scotland).

The article contributes to public relations research by offering a detailed analytical account of dialogue as a method of inquiry and a mechanism for change. The article also introduces the concept of extended epistemology as a fresh perspective on the phenomenon of relationship and relationship management. Finally, the article argues that action research has the transformative potential for the development of academic knowledge in the field and as an approach to education and training of practitioners. 


\section{Keywords}

action research, alcohol, dialogue, peer learning, public relations

\section{Introduction}

The project at the core of this article brings together two interests we have pursued in research and teaching for a few years: our interest in dialogue as a communicative practice, specifically in relation to claims laid to this area by public relations theory; and how communication can be used to help alleviate the problems caused for young people and their communities by the culture of excessive alcohol consumption in Scotland, recognized in research and recent public policy initiatives. At one level, the aim of this paper is to contribute to the stream of research in public relations concerned with dialogue (Taylor and Kent, 2002; Pieczka, 2011; Henderson and Bowley, 2010; Meisenbach and Feldner, 2009; Grunig, 2001; Pearson, 1989a), particularly by offering an example of dialogue as an effective way of communicating about health. At another level, the paper aims to raise questions about the nature of knowledge in public relations and links between knowledge and practice in the area.

The article starts by introducing background information in order to situate alcohol as a social issue in Scotland and to give an overview of the ways in which it has been researched and tackled through public policy in recent years. We then proceed with a discussion of action research and dialogue as an approach we have adopted in our project. The two sections that follow, 'The AlcoLOLs' and 'Knowledge and Action', present and analyze the work done by the AlcoLOLs, a group of 17 high school pupils and two academics (the authors of the paper) using a dialogic approach to develop peer education focused on the specific 
challenges posed by alcohol misuse amongst teenagers and young adults. We draw conclusions from this work in our final section, which reflects on the nature of knowledge utilized and produced by communication practitioners.

\section{Alcohol as a Social Problem in Scotland}

Alcohol misuse is a major and well-recognized social problem in Scotland, tackled both through recent legislation-Alcohol (Scotland) Act 2010; Alcohol (Minimum Pricing) Scotland) Act 2012-and a national strategy (Changing Scotland's Relationship with Alcohol: A Framework for Action, 2009) ${ }^{1}$. The scale of the problem has been quantified by a number of different measures, such as: rising consumption (11\% per capita between 1994-2009) accompanied by the falling price per unit of alcohol; the impact on health (in 2009 one in 20 deaths in Scotland was attributable to alcohol); the impact in terms of crime (70\% of assaults treated in hospital A\&E departments involved alcohol); and the impact in terms of productivity and the cost to the Scottish economy - in 2007 this was estimated at $£ 3.5$ billion, roughly equalling the turnover of the spirits and beer industry in Scotland that year (for more detail see Beeston et al, 2011).

Most policy effort in recent years has focused on: reducing alcohol consumption through amending licensing laws and the introduction of the Scottish Government's controversial minimum unit price policy; improved intervention and treatment; and attitude change (Scottish Government, 2010). Young people's drinking behavior has been identified as an area of special interest for policy makers and health professionals, as $17.5 \%$ of all deaths in the $16-24$ age

\footnotetext{
${ }^{1}$ Scotland has its own parliament with legislative powers over what are referred to as 'devolved' areas; health and education are among them. The powers are set out in Scotland Act 1998.
} 
group in Scotland are estimated to be caused by 'attributable alcohol conditions' (“Take action on alcohol...", 2011). As one element in the wide-ranging policy effort, in 2009 the Scottish Government established the Scottish Youth Commission on Alcohol (SYCA), a 12-month project set up to enable young people to conduct their own enquiry into the problem and make recommendations to the government. The commission reported in March 2010, and two of its recommendations caught our attention: '17. Promote and evaluate peer education approaches. 18. Young people should be co-designers of alcohol education and lifestyle education packages.' (SYCA, 2010a: 5). It was at this point that we decided to enter the field.

Our approach combined knowledge from the discipline of communication, specifically the development of deliberative and dialogic techniques in the context of policy making and community development (Gastil and Levine, 2005; Anderson et al, 2004: Gastil, 2008; OECD, 2009; Fisher, 2009, Pieczka, 2011;), with knowledge emerging from research on alcohol, focused on the question of the effectiveness of public health and education approaches.

In public relations, dialogue and two-way symmetrical communication, commonly understood as synonymous, have occupied a central position in the field's theoretical development, both as an influential normative statement about public relations practice and its social place (Pearson 1989 a, 1989b; Grunig and Grunig 1992) and as the focus of much critical debate (L'Etang and Pieczka, 1996, 2006; McKie and Munshi, 2007; Pieczka, 2011; Somerville and Kirby, 2012). This interest in dialogue was originally inspired by the developments in 
the field of communication more generally (Pieczka, 2011: 110-113) and it served public relations' need to address the ethical dilemmas at the heart of the practice and, consequently, its legitimacy. Despite its continued aspiration to symmetry and dialogue, the discipline has shown a poor understanding of the philosophy of dialogue and its practical tools in comparison to that demonstrated by other fields, such as public policy, community development, management or science communication (Pieczka, 2011, Wood and Escobar, 2011; Pieczka and Escobar, 2013; Pieczka and Ecsobar, 2010). Thus while our work aims to enrich public relations knowledge, it draws on other disciplines for conceptual and methodological support.

The accepted approach to health promotion, understood as "the process of enabling people to increase control over their health and its determinants" (WHO, 2005:1), works through "public policy, personal skills development, the creation of supportive environments, community participation and the reorientation of health services," (Kelleher, 1996:47). We have already pointed out such work relevant to alcohol health promotion in Scotland. It is important now to turn to health communication, generally acknowledged to play an important role in health promotion, and to the attention given to public health and education campaigns (Berry, 2007; Wright, Sparks and O’Hair, 2008; Thomas, 2006). Evidence gathered by the Scottish Youth Commission on Alcohol (2010b), demonstrates a heavy reliance on advertising and social marketing campaigns as communication practices routinely used in this area. As we see it, this points to a heavy reliance on transmission/persuasive models of communication based on information giving or creation and consumption of messages aimed at behaviour 
change. Young people have been extensively surveyed, but while there is a body of knowledge identifying and modelling the key factors relevant to their relationship with alcohol (Bremner et al, 2011; Cleveland et al, 2011; see also Smith and Foxcroft, 2009), effective ways of intervening in the growing alcohol epidemic prove somewhat elusive.

In our work we have turned to participatory, community-based approaches to the problem, seen as a way forward. In their study of teenage drinking Percy et al (2011) make this point in the following way:

Alcohol consumption is a social activity. It stands to reason, therefore, that the young people's drinking behaviour was influenced by the behaviour of others within their social world. However, the social processes underlying this influence cannot be reduced to simple ideas of peer pressure. Drinking culture evolved and developed over time and was shaped by the numerous social interactions between friends, as well as the group's relationship with the broader social environment (p.6)

The recognition of the importance of the concept of the relationship and the complexity of social relationships (peer group, small friendship groups, and family) seems to have led to increased attention being given to communication skills as the way in which relationships and group dynamics relevant to alcohol are enacted. For example, the National Institute for Health and Clinical Excellence (NICE) guidelines state that programmes should: 
provide the opportunity to explore attitudes to - and perceptions of alcohol use; help develop decision-making, assertiveness, coping, verbal /non-verbal skills and self esteem; increase awareness of how media, advertisements, role models and the views of parents peers and society can influence alcohol consumption (NICE Public Health Guidance 7, 2007: 6).

The Cochrane Intervention Review, in discussing the role of school-based psychosocial intervention programmes, focuses on their aim 'to develop psychological and social skills (e.g. peer resistance) through modelling, understanding, norm-setting and social skills practice, so that young people are less likely to misuse alcohol' (Foxcroft and Tsertsvadze, 2011: 4). The link between communications skills and peer education is highlighted by Velleman, who points to evidence recommending 'recruiting and engaging with peers to train them to become educators and attitude formation leaders [and that] influencing young people's views about normative drinking behaviour can have significant preventative effects' (2009: 31).

A relational paradigm for public relations, which focuses on establishing and maintaining relationships (as opposed to a communication paradigm focused on the design and implementation of persuasive or effective communication) was first proposed by Ferguson in 1984 but only developed with vigour more than a decade later by public relations scholars such as Broom, Casey and Ritchey (1997, 2000), Huang $(1997,2001)$ Hon and J. Grunig (1999), Ledingham and 
Bruning (1998, 1999, 2000) J. Grunig and Huang (2000) Toth

(2000) Ledingham $(2003,2006)$ and Ki and Hon (2012). There are clear commonalities in these various conceptualisations of relationship management: most emphasise the management of the impact of organizations' and publics' behaviours for strategic purposes and the process is often considered from an organizational perspective. Consequently, relationship is defined as a set of dimensions, which can be measured and nurtured for the achievement of effective organization-public relationships. Among the best known and most widely used (Kang 2013) is the scale developed by Hon and Grunig (1999) consisting of four indicators of relationship outcomes: trust, control mutuality, relationship commitment, relationship satisfaction; and two relationship types: communal relationships and exchange relationships. Despite a focused research effort, however, the quantitative bias can be seen as problematic, as Jahansoozie argues, such a "one-sided analysis using predetermined instruments that provide statistical data...does not provide a description of what the relationship is like and what it means for those involved in it' (2006:88). We reach to action research in search for an alternative way of thinking about communication, relationship, and action as will be demonstrated later.

To summarize, our project contributes to the body of knowledge and practice by experimenting with an approach that combines a number of elements: it follows the needs and knowledge exhibited by young people navigating their way through the challenge of learning about alcohol; it focuses on collaborative learning and a range of relevant communication skills; finally, it acknowledges the role played by the community context. The participants in our project learn 
within the context of shared public services and amenities, comparable exposure to mass media and access to alcohol, as well as links constituted through neighbourhood, family and, critically, the school as the focal point in their lives.

\section{Action Research}

Action research emerged in the social sciences in the mid-1940s as a new approach to inquiry, and possibly even a new paradigm, challenging the positivist notion of knowledge (Pasmore, 2006). The ambition to reshape knowledge production in the social sciences may not have delivered a full-scale paradigmatic change (Greenwood, 2002/2005; Reason and Torbert, $2001 / 2005)$, but the problem of reconnecting 'social action and social theory' (Peters and Robinson, 1984/2005: 46) has remained unresolved and continues to power the work conducted within the participatory worldview (Reason and Bradbury, 2006). While a number of definitions of action research exist (see Peters and Robinson, 1984/2005), as well as a range of action research practices, the variety is underpinned by a number of shared characteristics. In our research, we adopt Rapoport's rather loose definition: 'action research aims to contribute both to the practical concerns of people in an immediate problematic situation and to the goals of social science, by joint collaboration within a mutually acceptable ethical framework' (Rapoport, 1970 cited in Robinson, 1993/2005: 61).

There is a broad consensus in the literature on action research about its key defining characteristics: it is 'problem focused and directed toward the improvement of some existing social practice' (Peters and Robinson, 1984/2005: 
46); it is conducted in a collaborative manner with rather than on research participants; and it advances 'knowledge about the practice' (Robinson, 1993/2005: 60). Action research thus combines what traditional methods of inquiry separate-the informative and transformative aspects of knowledge about the human condition (Heron and Reason, 2006: 145). The interplay of the two is ensured by replacing the mutually exclusive 'roles of researcher and subject... by a co-operative relationship so that all those involved work together as co-researchers and co-subjects' (Heron and Reason, 2006: 144).

The approach to knowledge taken by action research is arguably its most important characteristic feature. Heron and Reason talk about its 'radical' or 'extended epistemology' (2006: 149). If the narrow epistemology characteristic of traditional research 'equates knowing with describing, explaining or understanding a phenomenon as an object' (Park, 2006. p. 85), extended epistemology introduces other categories of knowledge, defined by their form, utility, and focus on either the social performance of individuals (Park), or individual learning and performance (Heron and Reason). Thus for Park, representational knowledge (describing, explaining or understanding), is only one of three types of knowledge, the other two being: relational knowledge and reflective knowledge. The first of these refers to knowledge as relationship-not contained in objective propositions about objects, but understood as the performance of social relationships. Reflective knowledge for Park means actors' critical engagement with 'questions of morality and values relating to their life conditions and the proper action to take' (p.89). Heron and Reason (2006) offer a different typology, which is more focused on the stages of transformation of 
experience into 'theory' (experiential knowing, presentational knowing, propositional knowing), but which also recognizes the utility of knowledge to action through the category of practical knowing (skill, knack, competence).

The final feature of action research is its cyclical nature, represented as a cycle or a spiral with four distinct phases: planning, action, observation or reflection, and conceptualization. We will come back to these characteristic features of action research to reflect on the AlcoLOLs project later in the section 'Knowledge and action'.

\section{Dialogue as Action Research Practice}

When we embarked on our project, we were driven by two motivations: we wanted to make a real, immediate difference in people's lives, specifically, the lives of young people in a high school in our own local community; and we wanted to put to the test the knowledge we had about the transformative power of dialogue. While we wanted to make a contribution to the more general knowledge about the effectiveness of using specific communication approaches to support young people's learning about alcohol, we did not see such an outcome as the only legitimate goal to set. As we have shown above, the problem in alcohol research is not the lack of knowledge, but rather its kind; to quote the textbook action research view of traditional research: 'it doesn't help people find how to act to change things in their lives' (Heron and Reason, 2006: 143). The aim for us was to generate not only the kind of 'objective' knowledge recognized by most academic peer review processes, but a range of different types of 
knowledge consistent with the extended epistemology of action research and the specific 'method of inquiry' we employed-dialogue (Park, 2006: 84).

In the design of the project, we prioritized transformation over information, at least in the early stages. It was more important to us to work in ways that allowed our participants to co-create or shape the direction and outcomes of the collaborative work than it was to shoehorn the dynamics of the group's dialogue into answers to specific research questions posed before we started working as a group. We saw the project as an experiment in the sense in which Lewin understood it, as learning from practical action and change (1945/2005). We therefore made no assumptions about the specific knowledge we would derive from the experiment, but we were clear about its goals. In other words, in stetting two broad goals for the project, we talked about outcomes in terms of what they were for, rather than what they were to be:

- to produce a set of ideas and solutions for how young people can be assisted and encouraged in learning, together and from one another, about dealing with alcohol

- to deliver outcomes at the level of personal development for participants: our project aims to pilot a peer learning experience where participants learn how to communicate in a particular way (dialogue).

In order to achieve our goals, we designed an intervention, rather than applied a method of extracting data from the field. 
Dialogue seemed to us a promising approach to the problem at hand for two reasons. Firstly, as a communication method, it requires and fosters skills important to social relationships and learning, and, we postulated therefore, to tackling young people's specific relationship with alcohol, such as: (self)reflection, respect and civility, openness, constructive attentiveness to differences, and collaborative learning (Anderson et al, 2004; Isaacs, 1999). Secondly, communication methods routinely used in public health education in this area, as we have shown, have tended to focus on information giving or on attitude change through mass media campaigns. These, we argue, address 'statistical' rather than real people, and could be subverted or ignored in ways in which face-to-face engagement through dialogue could not.

Our approach was based on the recognition of dialogue as a method of both inquiry and will formation (Pieczka, 2011: 114; Linde, 2001), and consequently distinguished between dialogue and deliberation: 'Dialogue focuses on reciprocal understanding and relationship building, whereas deliberation is geared towards debating alternatives and making decisions' (Pieczka and Escobar, 2012, p.5; Anderson et al, 2004). Unlike public health campaigns, which we argue are often driven by the assumption of deficiency — such as, insufficient knowledge, unhelpful attitudes, or behaviour that does not measure up to a model of what is proposed as most beneficial — we started by focusing on collective capacity to generate knowledge, in the extended sense that action research gives it, within an appropriately constructed and conducted dialogue group process. We used a number of both dialogic and deliberative techniques (Gastil 2008), described in the following section, because our work had to fit in with a particular funding 
regime: we had to complete the project in 12 months and produce appreciative outcomes that could be conveyed in an evaluation narrative on completion of the project $^{2}$.

\section{The AlcoLOLs}

The project started in the autumn of 2010 as 'Peer Learning through Dialogue: Young People and Alcohol'. We approached Portobello High School (PHS) 3 , the largest publicly funded high school in Edinburgh, currently with an enrollment of around 1300 pupils, to let us conduct the project with their pupils. We were assisted in the recruitment of the participants by the Head Teacher who was briefed on our criteria (which specified, as far as possible, a mix of gender, socioeconomic and ethnic backgrounds, confidence levels and ages ranging from 13 to 18) and we were able to gather a group of 17 volunteers (incentivized by the promise of time out of lessons, an iTunes voucher and free lunches at the University). We conducted our first dialogue group in March 2011 and continued working with pupils until mid-June 2011, conducting 5 meetings, between 2-6 weeks apart, as the school schedule allowed. However, at the end of the school year, and almost at the end of the project as initially planned, we found our volunteers pitching to extend the project to their peers in the following year and

\footnotetext{
2 The project was supported by in 2010/11 by Edinburgh Beltane Public Engagement Challenge award. Beltane is one of the six UK Beacons for Public Engagement, an initiative jointly funded in 2008-2011 by the UK Higher Education Funding Councils, Research Council UK, and Wellcome Trust 'to build capacity for public engagement' in academic institutions. (http://www.publicengagement.ac.uk/about/beacons).

${ }^{3}$ In the Scottish system, secondary schools educate pupils between the ages of about 12/13 and 17/18. Pupils start in S1 and continue to S6. They can leave school at the age of 16 at the end of the S5 level.
} 
keen to take on the responsibility for running dialogue groups. The preparation and training for dialogue group facilitation and then running 15 groups, consisting of a mini series of two meetings each, was conducted in 2011/2012, reaching more than 180 pupils. It was in the winter of 2011 that the AlcoLOLs came into being.

The rest of this section tells the story of what the group did in a chronological order; while the following section, 'Knowledge and action', reflects on the events in a more analytical way while also offering more detail, selected to fit analytical, rather than narrative purposes.

\section{Year 1: 2010-2011}

Dialogue is powered by difference, not by consensus; dialogue also requires a safe space, which does not limit what one can say through fear of ridicule or other social sanctions (Wierzbicka, 2006, pp. 689-90 cited in Pieczka, 2011, pp.113-14). This meant that our group of volunteers had to be as diverse as we could make it, in the context of the school's population. 10 girls and 7 boys volunteered, with a range of ages between 14 and 18. Some of our participants were mature, confident, and keen to talk; others were quiet, a little shy, more comfortable to listen than to talk, at least initially 4 . We were all curious: they were curious to see what it was all about, curious about our university - where

\footnotetext{
${ }^{4}$ Please follow the link to the description of the project on QMU Centre for Dialogue page http://www.qmu.ac.uk/mcpa/cdial/AlcoLols.htm to see and listen to a number of our volunteers speaking.
} 
we brought them for the meetings; we (the authors of this paper) were curious to see how it would all turn out and how our ideas would work in practice.

Our meetings lasted 90 minutes; each of them having a different purpose and design.

The first meeting was designed to explain the project and how we as a group would work (ground rules), including the ethics and confidentiality of the proceedings. It was important to be clear about what was expected as well as to make active participation comfortable and, as much as possible, to establish it as the norm. We used the World Café format (Brown, 2005). The questions posed for the discussion followed from the theme of the recruitment leaflet 'Is it worth talking about alcohol?' but aimed to focus the conversations on reflection about communication practices and skills in relations to this topic.

The second meeting was devoted to storytelling. Stories and storytelling are recognized in dialogue research as perhaps the most important meaning-making practice and, therefore, a powerful force for action (Pearce and Pearce, 2004; Gastil, 2008, pp.36-37); they have also been turned into intervention tools, for example in the narrative recovery technique (Kellett, 1999; Kellett and Dalton, 2001), or in conflict dialogue, an approach to conflict management through conflict stories (Kellett, 2007). In our project, storytelling was used to bring into the open the diversity of experiences and to model and encourage the enactment of communication behaviours relevant to dialogue. The safe space was created through an agreement on confidentiality and advice on how to 'do' 
confidentiality, articulated in the participant's contract we constructed collaboratively. Skills we worked on included turn taking, listening and showing the commitment to the group by making a contribution, and these became the group's modus operandi from that point in time.

The third meeting started the deliberative phase: the decision making process about what recommendations the group would make to the school. We borrowed an aspect of deliberative techniques used in the public policy arena, such as the citizens' jury and consensus conference, namely the use of expert witnesses. We invited two university colleagues, members of the QMU's Alcohol Research Group, to speak about alcohol and young people and to answer the group's questions. The discussion in this session focused on understanding the problem that the group was dealing with: learning about alcohol.

The fourth session continued the deliberation. Much of the work was done in two smaller groups, each facilitated by one of the researchers. The final framework for understanding the problem and producing solutions was created jointly by the whole group towards the end of the meeting. While many of the elements used by the group to frame the problem were not new (for example, the link between the availability of leisure activities and drink consumption among young people; the importance of parents and peers), the identification of the need for a different type of communication is noteworthy. If public health-based information was seen as important (for example, to deliver factual knowledge of such as what a unit of alcohol is, or the recommended maximum level of consumption), there was also recognition that learning about alcohol involved 
more than such dry information, and that knowing useful things could come from a range of sources, in a variety of formats. Eventually, this element of the discussion led us to the importance of talking about alcohol, and the importance of telling stories - about oneself, about others - in a credible way. Much discussion was taken up with ways in which young people could manage the learning process, understood in very pragmatic ways: thinking about safety (drinking with people you know, in safe private places ${ }^{5}$ rather than on Arthur's Seat ${ }^{6}$ ), controlling the amount and type of alcohol drunk, as well as developing implicit understandings about the roles people take on in the group in relation to alcohol consumption and personal safety. Most importantly from our point of view, being able to talk about alcohol honestly and openly was seen as crucial.

The final meeting took place around a big table in the Head Teacher's office at the Portobello High School. The group were reporting on the work, presenting their findings, as discussed above, and making recommendations. The ideas that got to the top of the agenda were: an event for parents to convey what young people find helpful and effective and what does not work in conversations about alcohol at home; the enthusiasm about the usefulness of going through the dialogue project turned into the wish to make it possible for others in the school to have this experience.

\footnotetext{
${ }^{5}$ In Scotland it is legal for people under 18 to drink alcohol at home, at a friend's house, or on private properties; it is allowed for people over 16 to have a drink in a licensed establishment if accompanied by an adult and if the alcohol is consumed with a meal. People over 18 are allowed to buy alcohol and drink in public places http://www.youngscot.org/info/1631-alcohol-and-the$\underline{\text { law }}$

${ }^{6}$ Arthur's Seat is a hill (250m high) in Holyrood Park in Edinburgh, It's a popular hill walk and offers panoramic views of the city. It was also identified by the group as an area where serious underage drinking takes place.
} 
At this point we made a decision to come back to the school the following year and work with our group on developing our own intervention.

\section{Year 2: 2011-12}

Before we started working together with the group in the late autumn of 2011, we spent some time developing ideas about the best ways to organize facilitation training for our group and to build a dialogue process that would be suitable for peer education.

We had a number of intensive long sessions throughout December 2011 and January 2012. Early in December we reviewed the ideas from the summer and the group decided to prioritize the events for pupils, and to suspend the idea of an event for the parents, on the grounds encapsulated in the comment from one of the AlcoLOLs:

If my mum came and said, 'Oh, I've been at this amazing thing at the school that I want to sit down and talk about,' I'd just think [puts his head in his hands and shakes it ] no I don't want to know. The most important thing is to have the kids going home to the parents as opposed to the parents going home talking to the kids. One of the main things is that it's owned by pupils and not by parents (Fieldnotes, March 2012).

We were concerned about this ambitious plan on a number of levels: skills to facilitate groups, ethics of discussing sometimes illegal behviours, time constraints. Consequently, we worked with the AlcoLOLs to develop dialogic 
facilitation tools which they could use to enable their peer participants to talk about drinking behaviour without having to reveal any personal or intimate details.

We agreed to develop a 'talking film' and to use it as a tool for stimulating good quality dialogue in groups when time for the required ice breakers, learning dialogue skills and building relationships would be limited. We also came up with the idea of developing a board game, based on Snakes and Ladders ${ }^{7}$, as another prop for managing discussions and helping participants to identify appropriate strategies for navigating situations involving alcohol.

It was also at this point that the group realized that they needed to project a group identity, and settled on 'The AlcoLOLs'. We all liked the term because it encapsulates the humour and youth-centred spirit of the project (with LOL referring to the acronym Laugh Out Loud used in textspeak).

The filming of interviews took place over the Christmas holidays, producing many hours of material, from which two versions of the film were edited. The first version documents the AlcoLOLs' response to the dialogic approach for research purposes. The other version is designed to be used to facilitate dialogue groups at school. It shows a range of attitudes to and experiences of

\footnotetext{
7 'Snakes and Ladders (or Chutes and Ladders) is an ancient Indian board game regarded today as a worldwide classic. It is played between two or more players on a game board having numbered, gridded squares. A number of "ladders" and "snakes" (or "chutes") are pictured on the board, each connecting two specific board squares. The object of the game is to navigate one's game piece from the start (bottom square) to the finish (top square), helped or hindered by ladders and snakes, respectively. The historic version had roots in morality lessons, where a player's progression up the board represented a life journey complicated by virtues (ladders) and vices (snakes).' http://en.wikipedia.org/wiki/Snakes_and_Ladders
} 
(non)drinking gathered from interviews with both the AlcoLoLs and university students. During their subsequent dialogue groups at school, the AlcoLOLs pause the film to discuss questions relating to specific elements of the content. Despite our initial nervousness, the film proved a success, in the words of one of the AlcoLOLs,

Everyone was accepting of what we had to say and was impressed that we are really open about it [views on drinking]. People were jumping to tell us things that they learned and picked up [from the film] and the younger ones were listening to everything we said.

The starting idea for the game was to use the AlcoLOLs' own stories generated at various points of the process in the previous year, to construct scenario-based questions. After a few reiterations, we clarified the main idea of the game as modeling positive behaviours and attitudes. The game can be played in a number ways, depending on the group, but the key element remains unchanged: the judgments about whether the answer was good or poor-and whether a player can advance or has to retreat-should be made collectively by the players, according to the criteria offered as the rules (such as: engagement vs. posturing; self-reflection vs. preoccupation with oneself only and one's own feelings; good solutions vs. risky behaviour). What is rewarded, thus, is not factual knowledge about alcohol but the qualities that might be seen as good dialogue skills: ability to reflect, civility, empathy, openness, and consideration for others.

\section{Knowledge and action}


In order to make sense in a more analytical way of what this project has achieved, we will start by evaluating the project against the goals we initially set and then discuss it in terms of action research, with special attention given to the knowledge generated and utilized by the participants.

\section{Meeting the research goals}

The project has met its research goals. It offers young people a clear and innovative communication approach to managing their education about alcohol. The project has been extensively presented to a wide range of actors concerned with alcohol in terms of public health, education, crime, health interventions, and youth work. In March 2012, the AlcoLOLs were invited by their local Member of Scottish Parliament (MSP), Kenny MacAskill, Minister for Justice in the Scottish Government, to present the project in the Parliament to this group of policy stakeholders. We have received public praise and accepted invitations to present our project to teachers at Scotland's largest teaching conference, National Health Service professionals, and a conference organized by a charity active in funding work devoted to the problem of young people and alcohol. We have also received a grant from another charitable organization to extend our work to five schools in our local area, allowing us to access communities across the geographic area of north Edinburgh.

After the parliamentary reception, participants commented on the impact of the AlcoLOLs approach: 
I think it's very powerful, outstanding, it really drives home a message in a manner and a voice which is more likely to be listened to by young people. (Kenny MacAskill, interview, 28 March 2012)

I've been hugely impressed by the feedback which has been overwhelmingly positive and not just the written feedback - but the faces of people coming out of the AlcoLOLs' sessions at school, the comments that they made on the way past - it's just been great. The messages have been positive and insightful and the pupil leaders [the AlcoLOLs] have been courageous and committed. It's brought many, many rich rewards to them and their fellow pupils. (Peigi Macarthur, interview, 28 March 2012)

The interest in the project arises from the fact that it offers a genuine peer education project, which resonates with educators as well as social, health and youth workers, whose methods have been shaped by the humanistic psychology and person-centred psychotherapy, one of the most visible set of modern contributors to the development of dialogue (Pieczka, 2011).

At the level of personal outcomes, we have evidence of powerful impact on some of the AlcoLOLs in terms of behaviour, ability to reflect, and to communicate: the impact might be to change, or it might be the opposite, not to change one's ways, an equally good outcome for non-drinkers. We shall present more detailed evidence below in our discussion of knowledge generated by and within the project. 


\section{AlcoLOLs as action research}

In an earlier section of the paper, we outlined the characteristic features of action research to show how our project was guided by this philosophy in attempting to balance information with transformation. This section extends this line of analysis.

\section{Cycles of inquiry}

One of the features of action research is its use of 'inquiry cycles ... moving between reflection and action' (Heron and Reason, 2006: 145). We see the cycle as: planning, action, observation or reflection, and conceptualization. In our project, we can point to the first year (2010/2011) as an extended planning phase, followed by tight, smaller cycles of action and reflection throughout most of the second year (2011/2012), particularly from February to May when the AlcoLOLs ran their own dialogue groups in school. We had debriefing meetings to allow us all to discuss experiences of the facilitating teams (usually 4 AlcoLOLs facilitating a group of 12-15 pupils) and make adjustments to the way in which the dialogue groups ran (for example by implementing a policy of splitting up strong friendship groups because of their possible damaging effect on the safe space for dialogue). In October 2012 the project was able to secure funding 8 to be extended to five schools in the north of Edinburgh, this development being preceded by the work of conceptualization, needed for writing applications for funding, and followed by a further planning phase in which we are at the time of writing.

\footnotetext{
8 The funder is the Robertson Trust, an independent Scottish grant-making trust.
} 
The aim of this project was, as we said earlier, to make it possible for young people to take action to improve their practice of learning about alcohol. Our action research group, however, consisted of what might be referred to in this context as 'practitioners', i.e. the young people themselves, and the two initiating researchers, external to the practice by virtue of their ages. Given such differences in motivations for involvement, levels of knowledge, and roles in the group, it is also important to pay attention in the analysis to issues of power and ethics.

\section{Types of knowledge}

Reflective knowledge has been generated and displayed in abundance throughout the project. Here are some of the most striking examples.

One of the AlcoLOls, voted by her peers to be the worst drunk in the school in her year, looked back on her own troubled relationships with alcohol and the role she played in her friendship group. Anna ${ }^{9}$ saw herself as the one with the 'responsibility' in the group to make people laugh, to provide excitement and entertainment to her friends. Going through the dialogue process made her reassess both her own behaviour and her friends' attitude towards her to realize that she was trapped in an identity that was both alien and damaging. Ultimately, even though she did not use these words, her reflection is about the power of self-respect and dignity:

\footnotetext{
${ }^{9}$ We have changed participants' names in reporting their stories. Anna has changed the way in which she handles alcohol now.
} 
I would upstage everyone. I would do the most outrageous things...... it was my responsibility to make you laugh... I was doing this for you.....[but] They may laugh at you but nobody likes this person... I want to be able to be myself and not be in a blueprint that somebody else has invented for me.

For another AlcoLOL, a simple yet profound discovery was that his own behaviour was something to be proud of, an accomplishment to be publicly acknowledged and cherished, or as he put it 'Listening to all of them I realized... I'm doing alright.' At different points in the process, other participants reported what can be seen as a similar experience of suddenly seeing their own behaviour in a new light, thus making normative judgments about, in this case, imposing (wrong) expectations on others in relations to drinking. Betty's is a most striking story. Having reluctantly accepted the invitation to participate in a dialogue group run by her AlcoLOL peers at school, on leaving the room, Betty walked up to one of the researchers, and clearly upset, said, 'I just realized that I'd been pressurizing my friends to drink. I thought it was just a joke but it isn't. I want everybody in this school to see this film.'

Not surprisingly, in view of our earlier discussion of research on alcohol, relational and practical knowledge are often bound together. This is perhaps best illustrated by the AlcoLOLs' Snakes and Ladders game where challenges and solutions to do with drinking alcohol are always wrapped up with relationships: handling any of the game scenarios involves the use of communication skills that establish, maintain or alter the relative positions of the interlocutors and bonds between them. We experienced this in the project also when one of the 
participants used the AlcoLOLs' talking film as a way of introducing the topic of his own drinking to his parents, thus departing from his previous behavior of refusing to discuss the topic with them. While initially causing some pain, the move signaled the willingness to open up, to listen and empathize and, we surmise, altered subtly both his relationship with his parents.

Representational knowledge is perhaps most problematic and difficult to extract from the project at this stage. As our discussion of the cycle of inquiry demonstrates, the goals (and therefore research questions) have changed. While initially we wanted to know if dialogue could be used to deliver peer learning about alcohol, now we are asking whether such a process can operate in largely self-sustaining ways, what might be required to make it continue, and at what point and how it might translate into a noticeable effect at the community level. Although we did not pose such questions at the outset of the project, we now know that dialogue can produce transformative results in groups of young people, even in self-managed dialogue groups, and is an appropriate tool for peer education. This finding is in line with most of the literature on dialogue conducted in public policy processes or in organizations. At the same time, there is much we do not know about how this specific process works, and this too is knowledge.

\section{Role of researchers and ethics}

The humanistic tradition within which dialogue is situated and the nature of action research, bringing researcher and participants into a very close relationship, leads to increased sensitivity to 'interpersonal ethics - the care with 
which one treats another equal person, and social ethics, the concern with the results of one's research' (Rowan, 2006: 115). For us, an ethical issue that has proved somewhat challenging is that of balancing equality with difference: while dialogue as a technique is set up to maintain difference, it is also set up to exclude power. While difference of opinion is welcome, displays of power are not. The researchers were very conscious of having more power than the other group participants based on our institutional, expert and personal resources; we could no more leave all of this knowledge outside the dialogue group than we could detach ourselves from our bodies. However, following the rules of dialogue facilitation ultimately reduced the problem to making judgments about where, when and how our 'power' could be most helpful to making the AlcoLOLs' work possible. We did not and could not force decisions from the group, or their willingness to volunteer a lot of their time to the project, which participants took individually appropriately to their own circumstances (for example, voluntarily giving up days of their Christmas holidays to make the film and develop the game). We could, however, teach them how to facilitate, we could negotiate with the Head Teacher over a myriad of practical things the school had to allow us to do so that dialogue groups could run, we could help shape the film and the game, network to get their work known publicly, and write funding applications to enable the work to continue.

If action research produces useful knowledge in a collaborative manner, a good question to ask here is whose knowledge is embodied in this project and who benefits from it? We have strived to show that although different participants may have contributed in different ways, the collaborative process makes it 
possible for all participants to own the project. For example, as much as practically possible both the researchers and PHS pupils participated in public presentations, even in a meeting with the funders, though only the researchers could formally take the whole responsibility for delivering the project. We have also tried to ensure that all participants could draw benefits from this work, although to what extent the participants have been able to do so is a more complex matter. Some AlcoLOLs have grown and changed very visibly, and may have articulated it very clearly as well, but others perhaps not so. We are also working on finding ways to have the young volunteers' effort recognized through an existing scheme, and encouraging those applying for university places to put the AlcoLOLs experience in their personal statement.

The researchers have secured the ultimate academic prize-funding to enable the work to continue, and are in a position to work on publications, another source of academic recognition. In short, we point to ways in which all participants could transform the project into personal, professional or social resources. What is impossible to know at this stage is how this project might also make a bigger contribution to local communities or even possibly Scottish culture and public health.

\section{Reflections}

The work conducted in this project makes a contribution to public relations in three distinct ways: firstly, by offering an example of dialogic practice from which both practical and theoretical lessons can be learned; secondly, by encouraging fresh reflection on one of the key concepts in public relations, 
relationship; and thirdly, by rethinking the way in which the field has dealt with knowledge production and knowledge application in public relations.

Despite the prominence of dialogue as one of the fundamental concepts in public relations, it remains rather opaque as a public relations practice (Pieczka, 2011). This project, therefore, is useful in offering a detailed analytical account of the way in which a dialogic approach can be constructed and conducted, as well as the outcomes it may produce. While our case adds practical knowledge, by reaffirming that successful dialogue requires logistical knowledge about settings, pace of work, and the range of available communication techniques to be employed appropriately to the purpose (knowledge not normally covered by public relations textbooks), it also adds to theoretical reflection by working with the concept of extended epistemology (Park, 2006; Heron and Reason, 2006), which allows us to think about linkages between communication, knowledge and action in enriched ways.

As we have shown in this paper, relationship is a key concept not only for communication management, but has also attracted attention in other fields in our case, in the work of intervening in alcohol-related behaviours. In public relations theory, relationship management is based on, what Park (2006) calls, representational knowledge, which objectifies relationship by defining and measuring it as a set of dimensions, such as trust or satisfaction (see Ledingham, 2003, 2006, Ledingham and Bruning, 1998, 2000; Hon and Grunig, 1999; Huang, 2001). Our project has demonstrated that there is a fruitful alternative approach to thinking about the phenomenon of the relationship: focusing on the relational 
knowledge which is involved in the performance of social roles and actions. Our project has demonstrated very clearly how practical knowledge and action are entwined with relational knowledge, leading us to argue that understanding relationships in terms of what they practically achieve for people, rather than through numerical expressions of the amount of trust, for example, may be not only helpful but perhaps more appropriate in many instances where such a measurement is impractical for reasons of time or resources.

This leads us to consider briefly the way in which the public relations field has dealt with knowledge. Conducting an action research project - with rather than on people - has reminded us that both practitioners' and researchers' professional stance tends to reinforce the separation of roles between those who possess the knowledge and those to whom this knowledge is applied. Thus in research, even qualitative research, practitioners and their practice are described or interpreted by others according to academic models of knowledge. Consequently, it may be hard to apply knowledge produced in this way to solving practical problems in routine practice. We argue that adopting action research may be a way of developing useful knowledge with visible and immediate impact in practice. This line of thinking can be further extended to argue that it may be helpful to prepare young practitioners to think about their work as action research, where learning and change happen together, and where the nature of research/practice demands a non-instrumental approach to those who are traditionally seen as objects of professional attention and efforts - the stakeholders or publics. This might in fact reflect more accurately the exigencies of busy commercial practice, which does not normally allow practitioners to 
construct their work in ways driven by research questions or clear conceptualizations, in order to drive practice to achieve clean, successful outcomes. Negotiation, compromise and collaborative work (even if fraught with tensions and politics) however, may be a more realistic approach to understanding how practitioners work, and to teaching young practitioners how to operate in such contexts. It is not our intention to argue that action research is the only way forward, but we hope we have shown that it can make an interesting contribution to public relations.

\section{References}

"Take action on alcohol marketing and children" (15/08/2011) [News]. Available at http://www.alcohol-focus-scotland.org.uk/view/article/94-take-actionon-alcohol-marketing-and-children (accessed 15 July 2012).

Alcohol (Minimum Pricing) (Scotland) Act 2012). Available at http://www.legislation.gov.uk/asp/2012/4/pdfs/asp_20120004_en.pdf (accessed 30 November 2012).

Alcohol (Scotland) Act 2010. Available at http://www.legislation.gov.uk/asp/2010/18/pdfs/asp_20100018_en.pdf (accessed 30 November 2012).

Anderson R, Baxter L and Cissna K (eds) (2004) Dialogue: Theorizing Difference in Communication Studies. Thousand Oaks, CA: Sage.

Beeston C, Robinson M, Craig N, and Graham L (2011) Monitoring and Evaluating Scotland's Alcohol Strategy. Setting the Scene: Theory of Change and Baseline Picture. Edinburgh: NHS Health Scotland. 
Berry D (2007) Health Communication: Theory and Practice. Maidenhead: Open University Press.

Bremner P, Burnett J, Nunney F, Ravet M and Mistral W (June 2011) Young People, Alcohol and Influences. Joseph Rowntree Foundation. Available at http://www.jrf.org.uk/sites/files/jrf/young-people-alcohol-full.pdf (accessed 30 November 2012).

Broom G M Casey S. and Ritchey J (1997) Toward a concept and theory of organization-public relationships. Journal of Public Relations Research (2), 83-98.

Broom,G. M., Casey S. and Ritchey J (2000) Concept and theory of organizationpublic relationships, in Ledingham J A and Bruning SD (eds) Public Relations as Relationship Management: A Relational Approach to the Study and Practice of Public Relations. Mahwah, NJ: Lawrence Erlbaum Associates, 3-22.

Brown J (2005) The World Cafe': Shaping our Futures through Conversations that Matter. San Francisco, CA: Berrett-Koehler Publishers.

Cleveland M, Feinberg M, Osgood W and Moody J (2012) Do peers' parents matter? A new link between positive parenting and adolescent substance use. Journal of Studies on Alcohol and Drugs, 73(3), 423-33.

Ferguson M A (1984) Building Theory in Public Relations: Interorganizational Relationships as a Public Relations Paradigm. Paper presented to the Association for Education in Journalism and Mass Communication, Gainesville, FI, August.

Fisher, F. (2009). Democracy and Expertise. Oxford: Oxford University Press. 
Foxcroft D and Tzertsvadze A (2011) Universal school-based prevention programs for alcohol misuse in young people (Review). The Cochrane Collaboration. 5. John Wiley \& Sons. Available at www.thecochranelibrary.com/details/file/1064573/CD009113.html (accessed 30 November 2012).

Gastil J (2008) Political Communication and Deliberation. Thousand Oaks, CA: Sage.

Gastil J and Levine P (eds.) (2005) The Deliberative Democracy Handbook. San Francisco, CA: Jossey-Bass.

Greenwood D (2005) Action research: unfulfilled promises and unmet challenges. In B. Cooke and J. Wolfram Cox (eds) Fundamentals of Action Research, (vol. iv: pp. 173-95). London: Sage. (Reprinted from Concepts and Transformation, 2002, 7(2), 117-39).

Grunig J (2001) Two-way symmetrical public relations: Past, present and future. In Heath R (ed) Handbook of Public Relations. London: Sage, pp.11-30.

Grunig J and Grunig L (1992) Models of public relations and communication. In J Grunig (ed) Excellence in Public Relations and Communication Management, Hillsdale, NJ: Lawrence Erlbaum Associates, pp. 285-326.

Grunig, J and Huang YH (2000) From organizational effectiveness to relationship indicators: antecedents of relationships, public relations strategies and relationship outcomes. In Ledingham, JA and Bruning SD (eds) Public Relations as Relationship Management: A Relational Approach to the Study and Practice of Public Relations. Mahwah, NJ: Lawrence Erlbaum Associates, pp. 23-53 
Henderson A and Bowley R (2010) Authentic dialogue? The role of 'friendship' in a social media recruitment campaign, Journal of Communication Management, 14(3), $237-257$.

Heron J and Reason P (2006) The practice of co-operative inquiry: research 'with' rather than 'on' people. In P. Reason and H. Bradbury (eds) Handbook of Action Research. Thousand Oaks, CA: Sage, pp. 144-54.

Hon LC and Grunig JE (1999) Guidelines for Measuring Relationships in Public Relations. Gainesville, FL: Institute for Public Relations.

Huang Y (2001) OPRA: A cross-cultural multiple-item scale for measuring organization-public relationships. Journal of Public Relations Research, 13, $61-90$

Hung C F (2007) Toward a theory of relationship management in public relations: How to cultivate quality relationships? In Toth E (ed) The Future of Excellence in Public Relations and Communication Management. Mahwah, NJ: Lawrence Erlbaum, pp. 477-506.

Isaacs W (1999) Dialogue: and the Art of Thinking Together. New York, NY: Currency.

Jahansoozi, J (2006) Relationships, transparency and evaluation: the implications for public relations. In L’Etang J and Pieczka M (eds) Public Relations: Critical Debates and Contemporary Practice, Mahwah, NJ: Lawrence Erlbaum Associates, pp. 61-91.

Kang M (2013) Effects of the organization - public relational gap between experiential and expected relationship outcomes: Relational gap analysis. Journal of Communication Management, 17 (1) 40-55 
Kellett P and Dalton D (2001) Managing Conflict in a Negotiated World: A

Narrative Approach to Achieving Dialogue and Change. Thousand Oaks, CA: Sage.

Kellett P (1999) Dialogue and dialectics in managing organizational change. Southern Communication Journal, 64, 211-31.

Kellett P (2007) Conflict Dialogue. Thousand Oaks, CA: Sage.

Kent ML and Taylor M (2002) Toward a dialogic theory of public relations. Public Relations Review, 28(1), 21-37.

Ki E.-J and Hon LC (2012) Causal linkages among relationship quality perception, attitude, and behavior intention in a membership organization. Corporate Communication: An International Journal, 17 (2), 187-208.

Ledingham JA (2003) Explicating relationship management as a general theory of public relations, Journal of Public Relations Research, 15 (2) 181-198. Ledingham JA (2006) Relationship management: A general theory of public relations. In C.H. Botan \& V. Hazleton (eds.), Public Relations Theory II. Mahwah, NJ: Lawrence Erlbaum Associates, (pp. 465-483).

Ledingham JA and Bruning SD (1998) Relationship management in public relations: Dimensions of an organization-public relationship. Public Relations Review, 24, 55-65.

Ledingham JA and Bruning SD (2000) Public Relations as Relationship Management. Mahwah, NJ: Lawrence Erlbaum Associates.

L’Etang J and Pieczka M (eds) (1996) Critical Perspectives in Public Relations. London: International Thomson Business Press. 
L'Etang J and Pieczka M (eds) (2006) Public Relations: Critical Debates and Contemporary Practice. Mahwah, NJ: Lawrence Erlbaum Associates. Lewin K (2005) Action research and minority problems. In B. Cooke and J. Wolfram Cox (eds) Fundamentals of Action Research, (vol. i: pp. 19-31). London: Sage. (Reprinted from Journal of Social Issues, 1945, 2, 35-46).

Linder S (2001) An inquiry into dialogue, its challenges and justification. International Journal of Public Administration, 24 (7/8), 651-78.

McKie D and Munshi D (2007) Reconfiguring Public Relations: Ecology, Equity and Enterprise. Abingdon: Routledge.

Meisenbach R and Feldner S (2009) Dialogue, discourse ethics and Disney. In R. Heath, E. Toth, and D. Waymer (eds) Rhetorical and Critical Approaches to Public Relations II. New York: Routledge, pp. 253-271.

Organization for Economic Co-operation and Development (2009) Focus on Citizens: Public Engagement for Better Policy and Services. Paris: OECD. Park P (2006) Knowledge and participatory research. In P. Reason and H. Bradbury (eds) Handbook of Action Research. Thousand Oaks, CA: Sage, pp. 83-93.

Pasmore W (2006) Action research in the workplace; the socio-technical perspective. In P. Reason and H. Bradbury (eds) Handbook of Action Research. Thousand Oaks, CA: Sage, pp. 38-49.

Pearce WB and Pearce KA (2004) Taking a communication perspective on dialogue. In R. Anderson, L. Baxter, and K. Cissna, (eds) Dialogue: Theorizing Difference in Communication Studies. Thousand Oaks, CA: Sage, pp.39-56. 
Pearson R (1989a) Business ethics and: public relations practice and the idea of dialogue. In C.H Botan and V. Hazelton (eds) Public Relations Theory. Hillsdale, NJ: Lawrence Erlbaum Associates, pp.111-131.

Pearson R (1989b) Beyond ethical relativism in public relations: co-orientation, rules and the idea of communication symmetry. In J Gruning and L Gruning (eds) Public Relations Research Annual (vol1, pp 67-86). Hillsdale, NJ: Lawrence Erlbaum Associates.

Percy A, Wilson J, McCartan C and McCrystal P (February, 2011) Teenage Drinking Cultures. Joseph Rowntree Foundation. Available at http://www.jrf.org.uk/sites/files/jrf/teenage-drinking-culture-full.pdf (accessed 30 November 2012).

Peters M and Robinson V (2005) The origins and status of action research. In B. Cooke and J. Wolfram Cox (eds). Fundamentals of Action Research, (vol. iv: pp. 45-58). London: Sage. (Reprinted from Journal of Applied Behavioral Science, 1984, 20(2), 113-24).

Pieczka M (2011) Public relations as dialogic expertise? Journal of Communication Management, 15(2), 108-124.

Pieczka M and Escobar $O$ (2013) Dialogue and science: Innovation in policymaking and the discourse of public engagement in the U, Science and Public Policy,) 40(1), 113-126.

Pieczka M and Escobar (2010) The dialogic turn and management fashions. paper presented at the International Communication Association annual conference, Singapore. Available at http://eresearch.qmu.ac.uk/2923/ 
(accessed 3 March 2013).

Reason P and Bradbury H (2006) Introduction: Inquiry and participation in search of a world worthy of human aspiration. In P. Reason and H. Bradbury (eds) Handbook of Action Research, (pp. 1-14). Thousand Oaks, CA: Sage.

Reason P and Torbert W (2005) The action turn: toward transformational social science. In B. Cooke and J. Wolfram Cox (eds) Fundamentals of Action Research, (vol. iv: pp. 229-66). London: Sage. (Reprinted from Concepts and Transformation, 2001, 6(1): 1-37.)

Robinson V (2005) Current controversies in action research. In B. Cooke and J. Wolfram Cox (eds) Fundamentals of Action Research, (vol. iv, pp. 59-84). London: Sage. (Reprinted from Public Administration Quarterly, 1993, 17(3), 263-89).

Rowan J (2006) The humanistic approach to action research. In P. Reason and H. Bradbury (eds) Handbook of Action Research. Thousand Oaks, CA: Sage, pp. 106-115.

Scotland Act 1998. Available at http://www.legislation.gov.uk/ukpga/1998/46/contents (accessed 30 November 2012).

Scottish Government (March 2009) Changing Scotland's Relationship with Alcohol: A Framework for Action. Available at http://scotland.gov.uk/Publications/2009/03/04144703/0 (accessed 30 November 2012).

Scottish Government, (8 September 2010) Scottish Alcohol Research Framework. Available at http://www.scotland.gov.uk/Topics/Research/About/Social- 
Research/Work-Programmes/Scottish-Alcohol-Research (accessed 30 November 2012).

Scottish Youth Commissions on Alcohol (March 2010a) The Report of Recommendations. Available at http://www.youngscot.net/media/12177/syca_recommendations.pdf (accessed 30 November 2012).

Scottish Youth Commissions on Alcohol (March 2010b) The Report of Evidence. Available at http://www.youngscot.net/media/12177/syca_recommendations.pdf (accessed 30 November 2012).

Smith L and Foxcroft D (May 2009) Drinking in the UK: An Exploration of Trends. Joseph Rowntree Foundation. Available at http://www.jrf.org.uk/sites/files/jrf/UK-alcohol-trends-FULL.pdf (accessed on 12 February 2010).

Somerville I and Kirby S (2012) Public relations and the Northern Ireland peace process: Dissemination, reconciliation and the 'Good Friday Agreement' referendum campaign. Public Relations Inquiry, 1(3) 231-255.

Thomas R (2006) Health Communication. Boston: Springer.

Velleman R (2009) Children, Young People and Alcohol: How They Learn and How to Prevent Excessive Use. Joseph Rowntree Foundation. Available at http://www.jrf.org.uk/publications/young-people-alcohol- excessiveprevention (accessed 30 November 2012).

Wierzbicka A (2006) The concept of dialogue in cross-linguistic and crosscultural perspective. Discourse Studies, 8(5), 675-703. 
Wood E and Escobar 0 (2011) Using dialogue to reduce the turbulence: focussing on building social capital to encourage more sustainable PR goals and outcomes. Paper presented at Euprera 2011 Congress, September 8-10, 2011, Leeds.

World Health Organization (2005) The Bangkok Charter for Health Promotion in a Globalized World> Available at http://www.who.int/healthpromotion/conferences/6gchp/hpr_050829 \%20BCHP.pdf (accessed 5 March 2013).

Wright K, Sparks L and O'Hair D (2008) Health Communication in the 21st Century. Oxford:Blackwell. 